\title{
KONTEKS DALAM PERSPEKTIF CYBERPRAGMATICS
}

\author{
R. Kunjana Rahardi \\ Master Program of Indonesian Language and Literature Education \\ Sanata Dharma University Yogyakarta \\ kunjana.rahardi@gmail.com
}

\begin{abstract}
It is always possible to combine the field of language with other fields which may be irrelevant, but there is a possibility to develop the fields synergistically. Cyberpragmatics can be seen as a transdisciplinary field, because it includes complex dimensions, namely language, pragmatics, technology, media, internet, and possibly other dimensions as well. This article aims to describe contexts in cyberpragmatics. The data was collected from utterances in various domains which contained context entities. The substantive data source was taken from authentic texts in various social media which also contained context. As for the locative data source, it was from social media that could be reached within the time of research. The data was collected by applying listening method and interview method. The researcher also used his intuitive judgment given the fact that he is a native speaker of Indonesian language. The data analysis method applied in this research is distributional analysis method in order to reach the linguistic aspects of this research. The dominant analytical method used is the extralingual type of extralinguistic method of analysis. The analysis showed that various pragmatic contexts were found, which include social context, societal context, cultural context, and situational context. The diverse contexts may change and shift over time. The context of the past cannot be the same as the context of the present and future. The elements and functions of the context will definitely shift and change so that the meaning of speech intentions in cyberpragmatics will also change.
\end{abstract}

Keywords: Cyberpragmatics, social-societal context, cultural context, situational context

\begin{abstract}
Abstrak
Bidang bahasa sangat dimungkinkan berpadu dengan bidang lain yang mungkin sekali jauh tali-temalinya, tetapi sangat mungkin untuk dikembangkan secara sinergis. Cyberpragmatics bisa dipandang sebagai bidang transdisipliner bahasa karena di dalamnya terdapat dimensidimensi yang kompleks, yakni bahasa, pragmatik, teknologi, media, internet, dan mungkin masih ada dimensi-dimensi lainnya. Tulisan ini bertujuan mendeskripsikan wujud-wujud konteks dalam cyberpragmatics itu. Data dikumpulkan dari tuturan-tuturan dalam berbagai ranah yang disinyalir terdapat entitas konteks. Sumber data substantif penelitian ini berupa teks-teks autentik dari berbagai media sosial yang di dalamnya terkandung konteks. Adapun sumber data lokatifnya adalah media sosial yang dapat dijangkau di seputar waktu penelitian. Data dikumpulkan dengan menerapkan metode simak, khususnya yang bersifat bebas libat cakap. Selain metode simak, data juga dikumpulkan dengan menerapkan metode wawancara, baik yang sifatnya bersemuka maupun yang tidak bersemuka. Pembangkitan intuisi lingual peneliti juga dimungkinkan untuk menghasilkan data yang natural mengingat bahwa penulis adalah penutur asli bahasa yang sedang diteliti, yakni bahasa Indonesia. Metode analisis data yang diterapkan dalam penelitian ini adalah metode analisis distribusional untuk menjangkau aspek-aspek linguistik penelitian ini. Adapun metode analisis yang dominan digunakan adalah metode padan jenis ekstralingual. Hasil analisis
\end{abstract}


menunjukkan bahwa beragam konteks pragmatik ditemukan. Konteks tersebut meliputi konteks sosial, konteks sosietal, konteks kultural, dan konteks situasional. Konteks yang beragam itu berubah dan bergeser seiring dengan perubahan waktu. Konteks masa lalu tidak mungkin sama dengan konteks masa sekarang dan mendatang. Elemen dan fungsi konteks dipastikan bergeser dan berubah sehingga pemaknaan maksud tuturan dalam cyberpragmatics juga dipastikan berubah.

Kata Kunci: Cyberpragmatics, konteks sosial-sosietal, konteks kultural, konteks situasional

\section{PENDAHULUAN}

Perkembangan ilmu bahasa terjadi demikian pesat. Hal demikian tampak dari riset-riset yang telah dilakukan, baik dalam rangka akademik berkaitan dengan penyusunan skripsi, tesis, dan disertasi, maupun yang dilakukan dalam rangka riset-riset hibah dari pemerintah dan dari sumber-sumber eksternal. Semarak dan gelora riset bahasa itu bukan saja berobjek riset pada bidang-bidang internal bahasa, tetapi juga pada bidang-bidang eksternal bahasa (Alcón-Soler \& Yates, 2015; Rahardi, 2019). Dalam perspektif internal bahasa, riset-riset itu berkisar pada masalah-masalah yang terkait dengan entitas lingual dan pemakaian entitas lingual itu dalam linguistik. Riset tersebut dapat berkisar antara lingkup fonologi, morfologi, sintaksis, semantik, dan mungkin juga wacana, khususnya bagi yang mengimani bahwa wacana adalah salah satu kajian sintaksis (Wodak, 2007; Kecskes, 2012).

Dalam lingkup eksternal bahasa, riset-riset tersebut cenderung lebih berfokus pada aspekaspek pemakaian bahasa. Jadi, perspektif yang diterapkan adalah perspektif fungsional, bukan perspektif formal. Perspektif fungsional bahasa yang konstelasinya berada pada hierarki bahasa dan tatarannya yang tertinggi disebut dengan pragmatik. Pragmatik dibedakan menjadi dua, yakni yang bersifat umum (general pragmatics) dan yang bersifat kultur khusus (specific-culture pragmatics) (Goddard, 2004; Mills, 2009). Sementara itu, perspektif fungsional bahasa yang konstelasinya di sisi hierarki bahasa bertali-temali dengan masyarakat adalah sosiolinguistik, antropolinguistik untuk yang bertali-temali dengan budaya tertentu dan kelompok etnis tertentu, ekolinguistik untuk yang bertali-temali dengan lingkungan alamiah atau lingkungan metaforis, psikolinguistik untuk yang bertali-temali dengan kejiwaan dan pikiran seseorang, dan neurolinguistik untuk yang bertali-temali dengan syaraf dan pikiran, dan beberapa lagi bidang interdisipliner yang lain (Kecskes, 2012; Rahardi, 2019).

Selain bidang-bidang interdisipliner, hadir pula bidang multidisipliner bahasa, misalnya saja bidang ekopragmatik yang merupakan perpaduan tiga bidang studi, yakni bahasa, lingkungan, dan pragmatik (Rahardi \& Setyaningsih, 2019; Wimberley, 2017). Ada pula neuropragmatik, yakni yang memadukan bidang-bidang yang terkait dengan bahasa, syaraf, dan pragmatik (Unger, 2012). Arah perkembangan ke depan bukan lagi interdisipliner dan multidisipliner, tetapi transdisipliner. Bidang bahasa sangat dimungkinkan berpadu dengan bidang lain yang mungkin jauh tali-temalinya, tetapi sangat mungkin untuk dikembangkan secara sinergis. Penulis melihat bahwa cyberpragmatics (Locher, 2013a; Yus, 2011) sesungguhnya bisa dipandang sebagai bidang transdisipliner bahasa karena di dalamnya pasti terdapat dimensidimensi yang kompleks, yakni bahasa, pragmatik, peranti teknologi, wahana media, wahana internet, dan mungkin masih ada dimensi-dimensi lainnya yang terlibat di dalam cyberpragmatics tersebut (Locher, 2013b). 
Tulisan singkat ini mencoba mendeskripsikan wujud-wujud pergeseran konteks di dalam pragmatik tersebut. Adapun dimensi yang hendak digambarkan adalah dimensi elemen-elemen konteks dan dimensi fungsi-fungsi konteksnya (Rahardi, 2019). Adapun perspektif yang digunakan dalam penelitian ini adalah perspektif pragmatik, khususnya cyberpragmatics.

\section{TINJAUAN PUSTAKA}

Istilah cyberpragmatics ditelurkan oleh Fransisco Yus $(2001,2010)$ dan didefinisikan sebagai "Cyberpragmatics is an analysis of Internet-mediated communication from the perspective of cognitive pragmatics. It addresses a whole range of interactions that can be found on the Net: the web page, chat rooms, instant messaging, social networking sites, 3D virtual worlds, blogs, videoconference, e-mail, Twitter, etc. Of special interest is the role of intentions and the quality of interpretations when these Internet-mediated interactions take place, which is often affected by the textual properties of the medium." Dalam salah satu bidang pragmatik, apa pun jenis pragmatiknya, termasuk juga cyberpragmatics, hal yang harus sangat diperhatikan adalah konteks pragmatik (Yus, 2011; Locher, 2013a). Perbincangan ihwal pragmatik, apa pun jenis pragmatiknya, tidak akan dapat disebut sebagai pragmatik manakala konteks tidak dilibatkan di dalam perbincangan tersebut.

Dalam identifikasi penulis, setidaknya terdapat empat jenis konteks dalam studi pragmatik, yakni konteks sosial, konteks sosietal, konteks kultural, dan konteks situasional (Rahardi, 2018; 2017a). Konteks sosial bertali-temali dengan dimensi kemasyarakatan yang sifatnya horizontal. Hubungan sosial yang melibatkan individu-individu yang sifatnya sejajar atau sejawat, seperti hubungan antarmahasiswa, hubungan antardosen, hubungan antarkaryawan, hubungan antarpetani, dan hubungan antarpedagang adalah realisasi dari konteks yang sifatnya mendatar. Konteks sosietal berbeda dengan konteks sosial karena yang menjadi penentunya adalah hubungan sosial yang sifatnya vertikal; contohnya adalah hubungan antara dosen dan mahasiswa, hubungan antara atasan dengan karyawan atau dengan bawahan, hubungan antara pimpinan dengan pihak yang dipimpin.

Selanjutnya adalah konteks kultural yang menunjuk pada dimensi-dimensi asumsi budaya, baik yang sifatnya personal maupun komunal, pertimbangan-pertimbangan filosofis yang sifatnya tidak lepas dari aspek-aspek budaya lokal (Rahardi, 2016; Chen, 2017; Kramsch, 2002). Dalam kaitan dengan hal tersebut, pertimbangan konteks kultural untuk bahasa dan pemakaian bahasa di negara-negara Timur dan negara-negara Barat tentu sangat berbeda. Pertimbangan kultural wilayah-wilayah di Indonesia bagian barat, tengah, dan timur juga sangat jelas berbeda. Pertimbangan kultural yang bermacam-macam yang tidak sama antara satu dan lainnya itulah yang melahirkan perbedaan-perbedaan dalam norma interaksi dan norma interpretasi terhadap tuturan. Jenis konteks pragmatik yang terakhir adalah konteks situasional. Seorang antropolog ternama yang pertama-tama mengenalkan istilah konteks situasi adalah Bronislaw Kasper Malinowski (Kulkarni, 2014; Yu, 2011).

Konteks jenis ini dia sebut sebagai respons atas kesulitannya melaksanakan tugas etnografi di masyarakat Kiriwinia di Trobrian wilayah Lautan Pasifik. Dia berpandangan bahwa translasi bahasa dalam objek penelitiannya tidak dapat dilakukan tanpa menyertakan konteks situasinya. Dari pelahiran istilah konteks situasi oleh tokoh ini berkembanglah interpretasi dan elaborasi terhadap konteks dalam rangka studi yang berbeda-beda. Roman Jakobson memaknai konteks situasi dalam rangka kerja karya sastra (Jumanto, 2014; Jakobson, 1960). Geoffrey N. 
Leech mengelaborasi konteks menjadi sejumlah komponen, yakni penutur, mitra tutur, konteks tuturan, dan tuturan sebagai tindak verbal, dalam kerja komplementarianismenya. Dia menyebut dirinya dalam kerja kebahasaannya bukanlah bagian dari aliran semantikisme dan bukan pula bagian dari aliran pragmatikisme, melainkan semisemantikisme dan semipragmatikisme atau yang disebut sebagai komplementarianisme (Gretsch, 2009; Leech, 1983).

Dari pencermatan yang dilakukan penulis terhadap entitas konteks dalam pragmatik diperoleh sinyalemen bahwa konteks dalam pragmatik tersebut telah banyak bergeser pada era internet seperti sekarang ini. Konteks sosial yang semula telah ditengarai dengan ungkapan mnemonik SPEAKING oleh Dell Hymes (Dell, 1979; Rahardi, 2016), dan dijabarkan lebih lanjut oleh Soepomo Poedjosoedarmo dengan ungkapan memoteknik OOEMAUBICARA, semestinya sekarang perlu dicermati kembali perubahan dan pergeserannya. Demikian juga konteks kultural yang dijabarkan oleh Halliday dan konteks situsional yang dipaparkan oleh Geofrey N. Leech (Mey, Brown, \& Mey, 2006; Leech, 2007), sudah barang tentu perlu direinterpretasi dan dideskripsikan wujud-wujud pergeserannya seiring dengan perkembangan era internet yang terjadi sekarang ini.

Selanjutnya, teori relevansi Deirde Wilson and Daniel Sperber (1995) juga digunakan dalam tulisan ini sebagai peranti untuk mencermati data. Teori relevansi sesungguhnya hadir sebagai kritik atas prinsip kerja sama Grice (1975) dengan maksim-maksimnya. Mereka melihat bahwa maksim-maksim dalam prinsip kerja sama Grice tersebut saling bertumpukan atau bertumpang tindih antara satu dan yang lainnya. Selain itu, maksim-maksim dalam prinsip kerja sama tersebut juga dianggap tidak dapat berlaku sama dalam setiap masyarakat dan budaya. Oleh karena itu, Wilson \& Sperber (1995) menyatukan maksim-maksim yang bermacam-macam tersebut ke dalam satu prinsip saja, yakni teori relevansi. Dalam komunikasi yang bersifat ostensif, hal yang paling mendasar dan harus hadir adalah kesepahaman antarpenutur tentang hal yang sedang diperbincangkan itu (Jorgensen, 1996; Rahardi, 2017b). Dengan perkataan lain, kehadiran konteks menjadi sangat penting karena ketidakhadiran konteks akan melahirkan keambiguan dan kesalahpahaman. Akhirnya, perlu ditegaskan bahwa teori-teori yang dipaparkan di depan itu di dalam penelitian ini ditempatkan sebagai kerangka referensi (frame of reference) dan sebagai pisau analisis (tools of analysis) untuk membedah data penelitian ini.

\section{METODOLOGI}

Penelitian pergeseran elemen dan fungsi konteks sosial, sosietal, kultural, dan situasional ini berjenis deskriptif-kualitatif. Data dikumpulkan dari tuturan-tuturan dalam berbagai ranah kehidupan yang di dalamnya disinyalir terdapat fakta-fakta pergeseran konteks dalam studi pragmatik. Dengan demikian, objek sasaran penelitian ini adalah pergeseran elemen dan fungsi konteks itu sendiri. Sumber data substantif tuturan berupa teks-teks autentik dari berbagai media sosial yang di dalamnya terkandung fakta-fakta perubahan elemen dan fungsi konteks. Adapun sumber data lokatifnya adalah media-media sosial yang dapat dijangkau di seputar waktu penelitian, yakni media internet, pos-el (e-mail), Instagram, Whatsapp, dan sejenisnya. Data dikumpulkan dengan menerapkan metode simak, khususnya yang bersifat bebas libat cakap (Sudaryanto, 2016; Campisi \& Özyürek, 2013).

Dalam beberapa hal, diterapkan pula metode simak yang bersifat libat cakap. Selain metode simak, data juga dikumpulkan dengan menerapkan metode cakap, baik yang sifatnya semuka maupun yang sifatnya tidak semuka. Teknik cakap tersebut diterapkan kepada para 
mahasiswa perguruan tinggi dan siswa-siswa sekolah sebagai informan. Pembangkitan intuisi lingual peneliti juga dapat dilakukan untuk menghasilkan data yang natural mengingat bahwa penulis adalah penutur asli bahasa yang sedang diteliti, yakni bahasa Indonesia. Selanjutnya, perlu disampaikan pula bahwa instrumen penelitian ini adalah penulis sendiri mengingat bahwa penelitian ini menerapkan pendekatan kualitatif. Tahapan pengumpulan data berakhir setelah data terklasifikasi dan tertipifikasi dengan baik sesuai dengan objek penelitian dan rumusan masalah yang telah ditetapkan sebagai dasar dari klasifikasi dan tipifikasi tersebut (Lewis, Candlin and Mercer, 2007; Sudaryanto, 2016).

Langkah selanjutnya adalah analisis data. Metode analisis data yang diterapkan dalam penelitian ini adalah metode analisis distribusional untuk menjangkau aspek-aspek linguistik penelitian ini. Adapun metode analisis yang dominan digunakan adalah metode analisis padan jenis padan ekstralingual. Tahapan akhir penelitian ini adalah tahapan penyajian hasil analisis data. Hasil analisis data penelitian ini dilakukan dengan metode penyajian informal.

\section{HASIL PENELITIAN DAN PEMBAHASAN}

Hasil penelitian yang dilakukan terhadap sejumlah data dari media sosial menunjukkan hal-hal sebagai berikut. Pada cuplikan data 1 di bawah ini, terdapat percakapan antara P1 yang merupakan dosen sebuah perguruan tinggi dan P2 sebagai mahasiswa dari dosen di perguruan tinggi tersebut. Dialog bagian pertama secara lengkap disampaikan sebagai berikut.

\section{Data 1}

P2: Ada contohnya, Pak? Kebetulan saya masih di kampus...

P1: Di Klik saja. Pokoknya kovernya merah.

P2: Baik, Pak. Perkembangannya akan saya kabari!

P1: Siiiip!

Dari cuplikan tuturan tersebut tersirat maksud bahwa secara sosial, P1 dan PS memiliki status sosial yang tidak sama. PI memiliki status sosial yang lebih tinggi jika dibandingkan dengan P2. Dalam kaitan dengan jenis konteks di dalam pragmatik, sesungguhnya konteks sosietal melatarbelakangi hadirnya tuturan seperti yang disampaikan di atas ini (Cheung, 2010). Tuturan yang berbunyi, "Di Klik saja. Pokoknya kovernya merah." sekilas merupakan tuturan yang tidak memenuhi maksim kualitas dalam prinsip kerja sama Grice. Sebagai respons atas tuturan P2 yang berbunyi, "Ada contohnya, Pak? Kebetulan saya masih di kampus...", tentu saja respons P1 sangatlah tidak berkualitas. Akan tetapi, dalam perspektif Deirdre Wilson dan Dan Sperber dalam buku yang mereka susun, RELEVANCE: Communication \& Cognition, tuturan yang disampaikan P2 di atas bersifat relevan (Ifantidou, 2005; House, 2006).

Relevansi sebuah tuturan sama sekali tidak dapat dilepaskan dari latar belakang konteks hadirnya tuturan tersebut. Latar belakang tuturan tersebut berwujud asumsi-asumsi, baik yang sifatnya personal maupun komunal, yang menjadikan interpretasi terhadap sebuah tuturan menjadi relevan sekalipun tidak setia pada maksim-maksim dalam prinsip kerja sama Grice. Jadi, sudah terlihat bahwa interpretasi maksud tuturan itu telah bergeser normanya, dari semula yang terlampau bersifat Gricean Mindedness menjadi Wilsonian \& Sperberian Mindedness (Lee, 2001). Pergeseran juga terjadi bilamana tuturan di atas dibawa dalam konteks cyberpragmatics yang tidak lepas dari media sosial pada era internet seperti sekarang ini.

Sebagai dampak dari pemerantian teknologi, konteks sosietal yang mesti membatasi hubungan antara P1 dan P2 serasa menjadi semakin luntur dan lebur. Kadar distansi antara P1 
dan P2 semakin luruh dan serasa semakin tidak berjarak, seperti respons P1 dengan bentuk tuturan padat dan singkat, "Siiip!" sebagai respons atas tututan P2 yang berbunyi, "Baik, Pak. Perkembanganya akan saya kabari!" Tidak ada keambiguan pemahaman antara bentuk, “... perkembangannya akan saya kabari” dan "...perkembangannya akan saya kabarkan”. Secara linguistis, bentuk yang benar tentu saja adalah bentuk yang kedua. Sekali lagi, keambiguan atau ketaksaan itu menjadi sirna karena konteks dipertimbangkan secara signifikan dalam memaknai tuturan tersebut. Nuansa kedekatan relasi di antara P1 dan P2 sangat kentara, sekalipun kedekatan tersebut hanya dalam konteks akademik di kampus. Dengan perkataan lain, sekat-sekat konteks sosietal luruh seolah-olah bergeser menjadi konteks sosial yang berdimensi horizontal, konteks yang berdimensi kesejawatan (Cheung, 2010). Selanjutnya, bagian kedua dari cuplikan tuturan dalam Whatsapp 1 adalah sebagai berikut.

\section{Data 2}

P1: Pagi ini bisa diserahkan ke saya mbak sekalian pdfnya yah.

P2: Baik Pak... Pukul berapa Bapak tiba di kampus?

P1: 8 yah.

P2: Baik, Pak. Pdfnya kirim email saja atau bagaimana Pak?

P1: Tapi Bu yuli dan saya tanda tangan dulu di riwayat hidup dan pengesahan. Baru pdf.

P2: Baik Pak!

$\mathrm{P} 1$ : Sebelum ketemu saya tlng ke ruang 30 ketemu Bu Yuli minta tanda tangan ya.

P2: Baik Pak...

Dimensi relevansi dari cuplikan tuturan di atas adalah bahwa P1 sebagai seorang dosen berbicara secara kontekstual kepada P2 yang adalah mahasiswanya di Program S-2. Dimensi relevansi juga ditunjukkan oleh $\mathrm{P} 2$ sebagai mahasiswa, yang tampak berbicara dengan penuh pertimbangan kepada P1. Sekalipun P1 telah berusaha menggeser nada tuturnya kepada P2, tetap saja P2 konsisten pada asumsi personal dan komunalnya bahwa P1 adalah sosok yang harus dihargai dan dihormati. Tuturan P1 yang menggunakan bentuk-bentuk kebahasaan yang tidak formal seperti pada, "Pagi ini bisa diserahkan ke saya mbak sekalian pdfnya yah" dan pada cuplikan tuturan berikutnya yang berbunyi, "8 yah", selalu direspons formal oleh P2 dengan bentuk tuturan, "Baik Pak...Pukul berapa Bapak tiba di kampus?" dan tuturan, "Baik, Pak. Pdfnya kirim email saja atau bagaimana Pak?"

Dengan demikian, dapat ditegaskan bahwa elemen dan fungsi konteks tetap tidak berubah bagi kedua belah pihak dalam cuplikan tuturan di atas. Jika dilihat dari substansi maksim kualitas, tuturan yang disampaikan oleh P1 yang berbunyi, "Tapi Bu yuli dan saya tanda tangan dulu di riwayat hidup dan pengesahan. Baru pdf" sebagai respons atau tuturan P1 yang berbunyi, "Baik, Pak. Pdfnya kirim email saja atau bagaimana Pak?" memiliki kualitas yang rendah. Pasalnya, tuturan itu tidak menanggapi tuturan yang disampaikan sebelumnya. Akan tetapi, dari prinsip relevansi dalam komunikasi dan kognisi, tuturan di atas tetap dapat dianggap relevan (Nicolle \& Clark, 1998). Penulis hendak mengatakan bahwa pertimbangan relevansi sesungguhnya identik dengan pertimbangan kontekstual. Tuturan yang kontekstual sudah barang tentu bersifat relevan. Data cuplikan tuturan-tuturan di atas secara lengkap dapat dicermati pada data di bawah ini. 


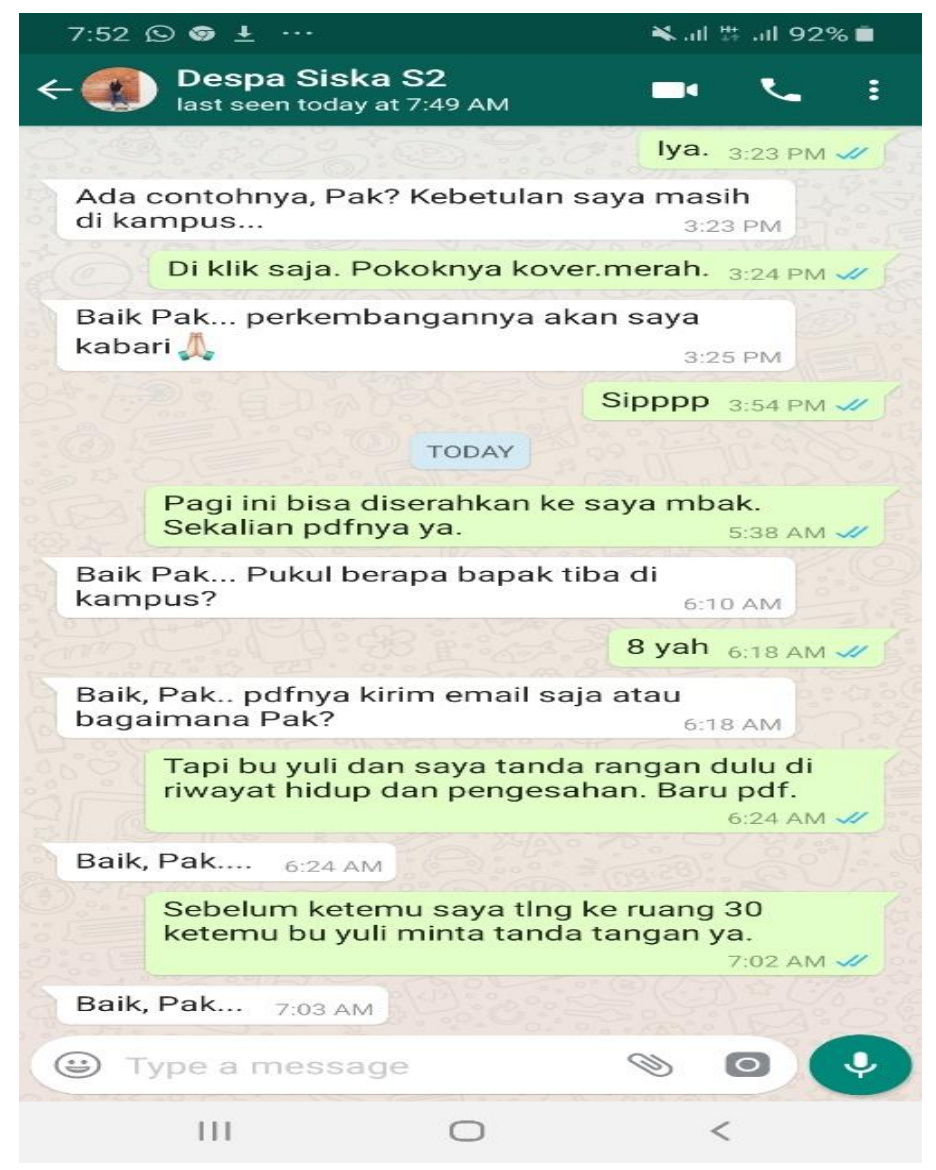

Gambar 1. Data Whatsapp 1

Selanjutnya, pada cuplikan bagian 1 dari data 2 berikut ini dapat pula dicermati fakta pergeseran elemen dan fungsi konteksnya. Cuplikan tuturan pertama adalah sebagai berikut.

\section{Data 3}

P1: Mas Agus saya mo perawatan HRV hitam besok jam 11 bisa ya. Tks. Harga Pak Kunjana berapa?

P2: Siap Pak Kunjana....besok bisa masuk....harga masih sama 250rb buat Bapak.

P1: Ok. Tapi optimal yah.

P2: Siap Pak Kunjana.

Dari cuplikan tuturan dalam media sosial di atas tampak bahwa hubungan antara P1 dan P2 sudah cukup dekat. P1 yang merupakan pemilik mobil HRV hitam memesan waktu untuk perawatan mobil. Sekaligus, P1 menanyakan harga khusus seperti yang lazimnya dikenakan kepadanya. Respons dari P2 demikian baik dan antusias. Wujud jawaban itu sekaligus menunjukkan bahwa relasi bisnis yang telah terbangun di antara keduanya telah berjalan sangat baik. Dari cuplikan tuturan tersebut kelihatan bahwa kedua belah pihak telah memiliki latar belakang pengetahuan yang sama-sama dimiliki. Jadi, baik P1 maupun P2 sama-sama mengetahui bahwa perawatan lapis cat ceramik Scuto perlu perawatan periodik. Tanpa ada kata-kata lapis cat keramik Scuto, tututan di antara keduanya sudah saling dipahami secara baik. Selain itu, dalam konteks cyberpragmatics (Locher, 2013b), keduanya juga sama-sama memahami tentang harga khusus yang biasa diberikan oleh P2 kepada P1. 
Hal tersebut tampak dari bentuk tuturan, "Harga masih sama 250 ribu buat Bapak." Cuplikan tuturan pada data 2 tersebut benar-benar menegaskan bahwa konteks pragmatik benarbenar sangat penting untuk memahami makna pragmatik atau maksud penutur. Selanjutnya, tuturan P1 yang berbunyi, "OK. Tapi optimal yah" dan direspons oleh P2 dengan tuturan, "siap Pak Kunjana" benar-benar menunjukkan bahwa asumsi-asumsi personal dan komunal sebagai hakikat konteks telah sama-sama dipahami oleh penutur dan mitra tutur. Cuplikan tuturan lengkap dari yang telah dipaparkan di atas dapat dicermati pada hasil tangkap layar teks Whatsapp di media sosial berikut ini.

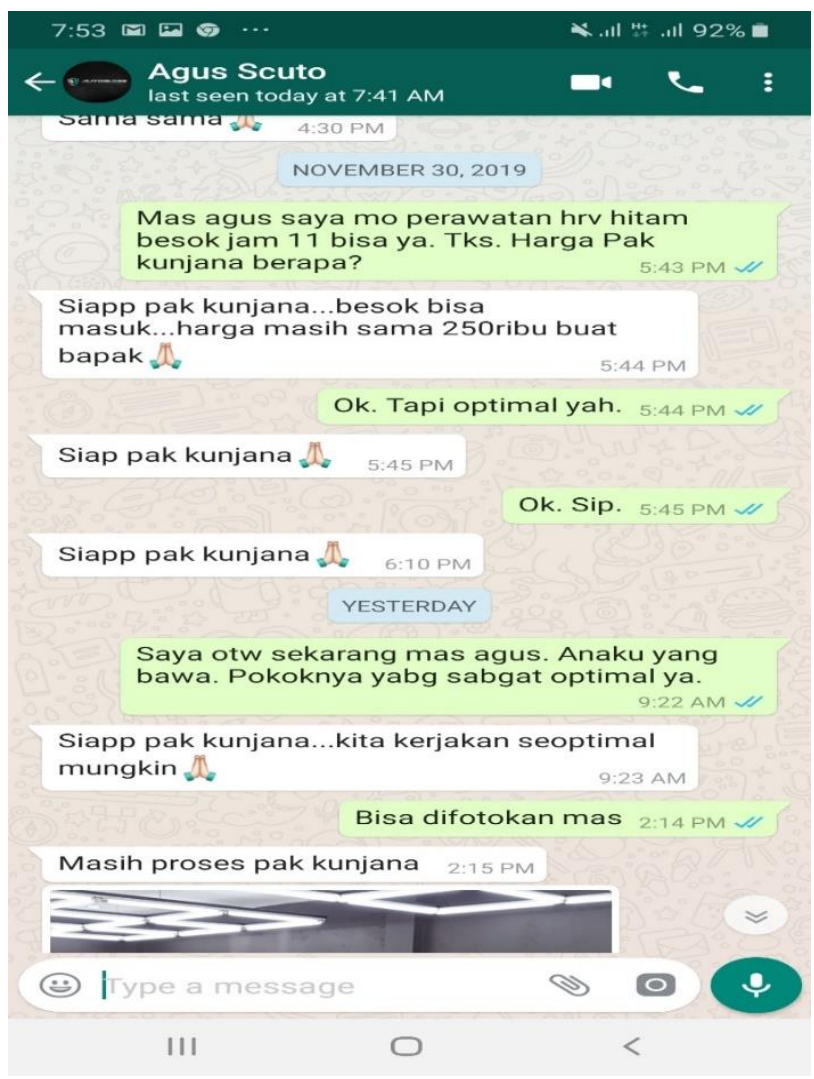

Gambar 2. Data Whatsapp 2

Data berikut ini perlu disampaikan kembali supaya menjadi semakin jelas.

\section{Data 4}

P1: Menunggu hujan setelah tugas negara.

P2: Acara opo kang neng GKN Bandung?

P1: Menyeleksi beasiswa LPDP bosqu.

Cuplikan tuturan di atas hadir dalam konteks cyberpragmatics (Yus, 2011). P1 dengan serta-merta mengunggah tuturan yang berbunyi, "Menunggu hujan setelah tugas negara" disertai foto yang menunjukkan bahwa situasi memang sedang hujan. Tuturan tersebut direspons oleh seseorang, mungkin saja seseorang yang sudah berhubungan dengan sangat erat dengan P1, dengan tuturan akrab yang berbunyi, “Acara opo kang neng GKN Bandung?" Hadirnya bentuk kang yang dalam bahasa Indonesia menjadi 'Mas' atau 'Kak' menunjukkan bahwa P1 dan P2 sudah memiliki hubungan yang dekat. Sapaan akrab demikian itu tidak mungkn disampaikan pada 
seseorang yang belum berelasi dekat (Wildner-Bassett, 2004). Respons lanjutan dari P1 yang berbunyi, "Menyeleksi beasiswa LPDP bosqu" terhadap tuturan sebelumnya juga sekaligus menegaskan bahwa P1 berelasi akrab dengan P2. Variasi pemakaian bentuk klitika jenis enklitika $-k u$ menjadi - $q u$ adalah penanda lain dari kelekatan hubungan itu. Bentuk kebahasaan yang tidak standar seperti yang terdapat pada tuturan di atas hanya mungkin digunakan kepada orang yang memiliki hubungan khusus.

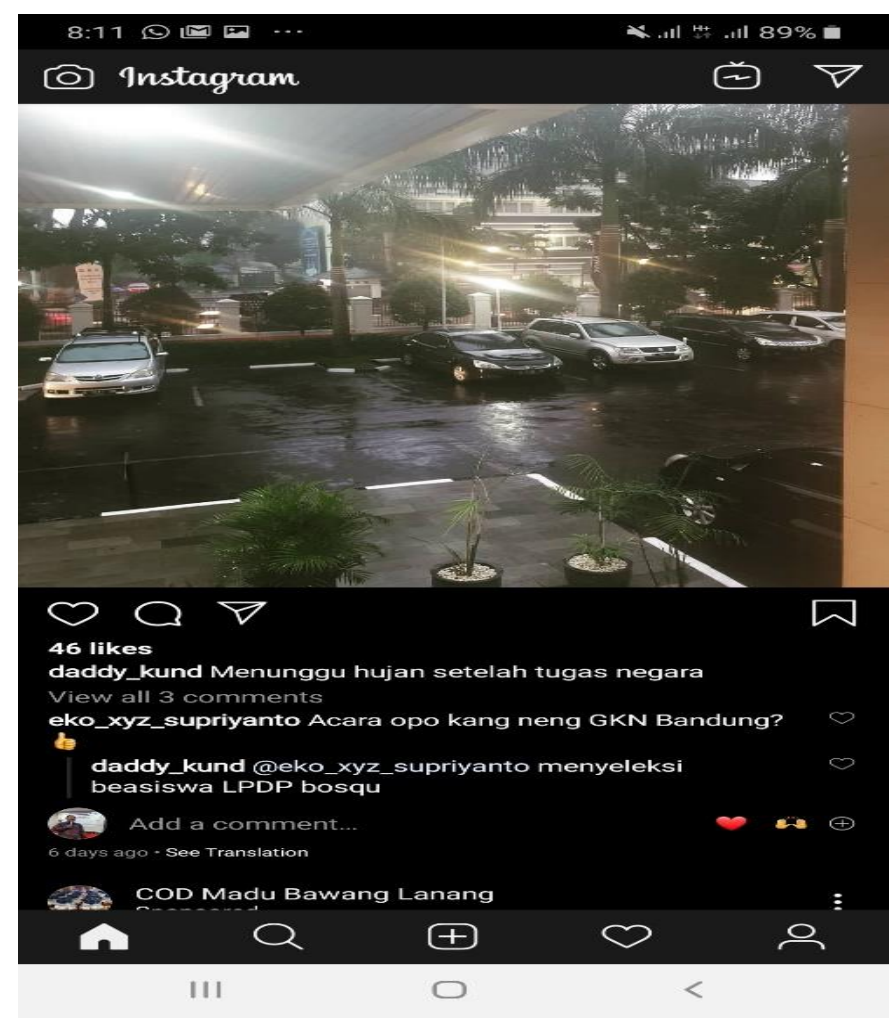

Gambar 3. Data Instagram 1

Data berikut ini berisi informasi tentang sampel surat. Secara lengkap, substansi surat tersebut disampaikan sebagai berikut.

\section{Data 5}

Bapak Kunjana Rahardi. Pak Kun, melalui surel ini perkenankanlah saya menyampaikan sample surat-surat di Fakultas Psikologi yang dibutuhkan untuk bahan pembelajaran dalam workshop Korespondensi Laras Dinas bagi tenaga kependidikan Fakultas Psikologi. Jika masih dibutuhkan adanya kebutuhan sample surat, kami segera menindaklanjutinya. Terima kasih. Salam hormat.

Cuplikan tuturan dalam pos-el di atas mengandung konteks relasi sosial dan sosietal bahwa pihak pengirim surat memiliki status sosial yang lebih rendah daripada pihak penerima surat, yaitu yang satu sebagai tenaga kependidikan sebuah fakultas, yang satu adalah dosen senior di fakultas yang berbeda. Nada surat menunjukkan hubungan sosial vertikal termaksud. Dari sisi konteks kulturalnya (Meyer, Halliday, \& Hasan, 2006) tampak pula bahwa keduanya berasal dari suku yang sama, yakni Jawa. Cara menghormati orang lain, tata krama yang diterapkan melalui bahasa surat, semuanya menunjukkan bahwa pengirim surat dan penerima surat berasal dari 
konteks kultur yang sama, yakni sama-sama berasal dari Jawa. Selanjutnya, berdasarkan pertimbangan konteks situasi suratnya, surat tersebut berada pada situasi formal. Sekalipun demikian, pemakaian bentuk-bentuk kebahasaan yang bernuansa akrab, seperti Pak Kun, menunjukkan bahwa terdapat pula unsur kedekatan relasi dalam surat tersebut. Sebaliknya, bentuk perkenankanlah saya menyampaikan... menunjukkan bahwa pengirim surat adalah seseorang yang sangat menghormati si penerima surat.

Dengan demikian, jelas bahwa dalam perspektif cyberpragmatik, konteks pesan di dalam surat elektronik dapat diperikan, entah itu yang termasuk konteks sosial, konteks sosietal, konteks kultural, ataupun konteks situasional (Rahardi, 2018). Konteks demikian itu bergeser seiring dengan perubahan waktu. Konteks yang terdapat dalam surat elektronik pada masa lampau tentu berbeda dengan konteks elektronik pada masa-masa digital dan era elektronik seperti sekarang ini. Cuplikan surat elektronik berikut dapat dicermati lebih lanjut untuk memperjelas hal ini.

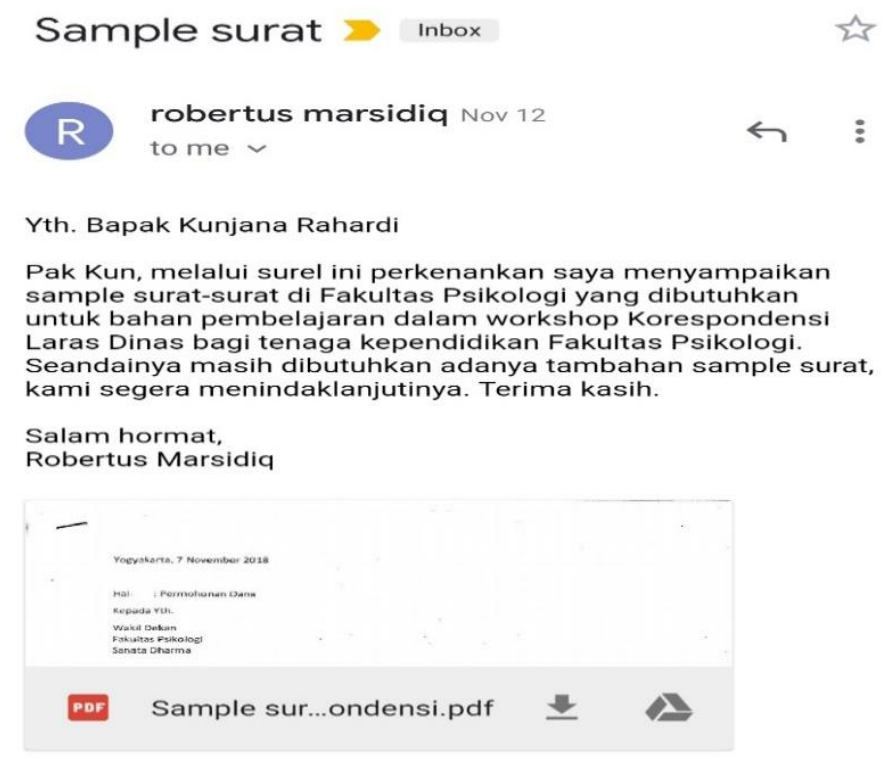

Gambar 4. Data Pos-el 1

Analisis terhadap data yang berasal dari berbagai media sosial di atas menunjukkan bahwa objek sasaran penelitian dalam bidang pragmatik bergeser seiring dengan perguliran waktu. Aspek pragmatik yang sangat penting sebagai penentu maksud tuturan, yakni konteks pragmatik yang dapat diperinci menjadi konteks sosial, sosietal, kultural, dan situasional (Rahardi, 2019), juga senantiasa bergeser seiring dengan guliran waktu. Kenyataan kebahasaan demikian ini menegaskan bahwa substansi pembelajaran pragmatik di perguruan tinggi perlu berubah menyesuaikan perubahan zaman.

\section{SIMPULAN}

Sebagai penutup, perlu disampaikan bahwa dengan menganalisis data tuturan yang diambil dari media sosial sebagai sumber data lokasional ditemukan konteks pragmatik yang beragam, yaitu meliputi konteks sosial, konteks sosietal, konteks kultural, dan konteks situasional. Semakin variatif data yang dianalisis, semakin jelas kelihatan bahwa entitas konteks yang beragam muncul dalam data penelitian tersebut. Selanjutnya, data yang beragam itu juga berubah dan bergeser 
seiring dengan perubahan zaman. Konteks masa lalu, tidak mungkin sama dengan konteks masa sekarang dan masa mendatang. Elemen dan fungsi konteks dipastikan akan bergeser dan berubah sehingga pemaknaan maksud tuturan juga dipastikan akan berubah. Penelitian ini masih terbatas pada data media sosial yang berupa pesan, Whatsapp, Instagram, dan surat elektronik. Data yang lebih beragam dipastikan akan menghasilkan bukti-bukti pergeseran elemen dan fungsi konteks yang lebih baik. Berkaitan dengan hal tersebut, penelitian-penelitian sebidang disarankan untuk segera dilakukan agar cyberpragmatik semakin berkembang dengan optimal.

\section{UCAPAN TERIMA KASIH}

Penulis mengucapkan terima kasih kepada pihak-pihak yang membantu penelitian ini, mendanai penelitian ini, khususnya DRPM, Kemenristekdikti, RI dalam Skema Hibah Terapan 2019-2022.

\section{DAFTAR PUSTAKA}

Alcón-Soler, E., \& Yates, L. (2015). Editors' introduction to pragmatic learning across contexts. System. https://doi.org/10.1016/j.system.2014.09.012

Campisi, E., \& Özyürek, A. (2013). Iconicity as a communicative strategy: Recipient design in multimodal demonstrations for adults and children. Journal of Pragmatics. https://doi.org/10.1016/j.pragma.2012.12.007

Chen, J. (2017). Research Trends in Intercultural Pragmatics. Australian Journal of Linguistics. https://doi.org/10.1080/07268602.2016.1204903

Cheung, M. (2010). The globalization and localization of persuasive marketing communication: A cross-linguistic socio-cultural analysis. Journal of Pragmatics. https://doi.org/10.1016/j.pragma.2009.06.012

Dell, H. (1979). Foundations in sociolinguistics: An ethnographic approach. Journal of Linguistics. https://doi.org/10.1017/S0022226700013256

Goddard, C. (2004). Speech-acts, values and cultural scripts: A study in Malay ethnopragmatics. Dalam Asia Examined: Proceedings of the 15th Biennial Conference of the ASAA, 2004, Canberra, Australia.

Gretsch, C. (2009). Pragmatics and integrational linguistics. Language and Communication. https://doi.org/10.1016/j.langcom.2009.02.010

House, J. (2006). Constructing a context with intonation. Journal of Pragmatics. https://doi.org/10.1016/j.pragma.2005.07.005

Ifantidou, E. (2005). The semantics and pragmatics of metadiscourse. Journal of Pragmatics. https://doi.org/10.1016/j.pragma.2004.11.006

Jakobson, R. (1960). Linguistics and poetics. Dalam Style in language. https://doi.org/10.1002/car.1158

Jorgensen, J. (1996). The functions of sarcastic irony in speech. Journal of Pragmatics. https://doi.org/10.1016/0378-2166(95)00067-4

Jumanto. (2014). Phatic communication: How english native speakers create ties of union. American Journal of Linguistics. https://doi.org/10.5923/j.linguistics.20140301.02 
Kecskes, I. (2012). Sociopragmatics and cross-cultural and intercultural studies. Dalam The Cambridge Handbook of Pragmatics. https://doi.org/DOI: 10.1017/CBO9781139022453.033

Kramsch, C. (2002). Language and culture: A social semiotic perspective. Adfl. https://doi.org/10.1632/adfl.33.2.8

Kulkarni, D. (2014). Exploring Jakobson's "phatic function" in instant messaging interactions. Discourse and Communication. https://doi.org/10.1177/1750481313507150

Kunjana Rahardi, R. (2016). Manifestasi wujud dan makna pragmatik kefatisan berbahasa dalam ranah pendidikan. Adabiyyāt: Jurnal Bahasa dan Sastra. https://doi.org/10.14421/ADB.V15I2.939

Lee, B. P. H. (2001). Mutual knowledge, background knowledge and shared beliefs: Their roles in establishing common ground. Journal of Pragmatics. https://doi.org/10.1016/S03782166(99)00128-9

Leech, G. (1983). Principles of pragmatics. Journal of Linguistics. https://doi.org/10.1017/S0022226700010367

Leech, G. (2007). Politeness: Is there an East-West divide? Journal of Politeness Research. https://doi.org/10.1515/PR.2007.009

Lewis, M., Candlin, C. N., \& Mercer, N. (2007). English language teaching in its social context. TESOL Quarterly. https://doi.org/10.2307/3588440

Locher, M. A. (2013a). Cyberpragmatics: Internet-mediated communication in context. Journal of Pragmatics. https://doi.org/10.1016/j.pragma.2012.12.002

Locher, M. A. (2013b). Cyberpragmatics: Internet-mediated communication in context. Journal of Pragmatics. https://doi.org/10.1016/j.pragma.2012.12.002

Mey, J. L. L., Brown, K., \& Mey, J. L. L. (2006). Pragmatics: Overview. Dalam Encyclodpedia of language and linguistics. https://doi.org/10.1002/9781405198431.wbeal1338

Meyer, C. F., Halliday, M. A. K., \& Hasan, R. (2006). Language, context, and text: Aspects of language in a social-semiotic perspective. TESOL Quarterly. https://doi.org/10.2307/3586740

Mills, S. (2009). Impoliteness in a cultural context. Journal of Pragmatics. https://doi.org/10.1016/j.pragma.2008.10.014

Nicolle, S., \& Clark, B. (1998). Phatic interpretations: Standarisation and conventionalisation. Revista Alicantina de Estudios Ingleses. https://doi.org/10.14198/raei.1998.11.14

Rahardi, R. K. \& Setyaningsih, Y. (2019). Contextualizing local values of children's games in the perspective of ecopragmatics to enhance culture-specific based communication. International Journal of Engineering and Advanced Technology (IJEAT), 9(Issue-1, October 2019), 143-151. https://doi.org/DOI: 10.35940/ijeat.A1096.109119

Rahardi, K. (2019). Pragmatic perspective on phatic functions and language dignity in a culturebased society. Asia Proceedings of Social Sciences. https://doi.org/10.31580/apss.v4i1.554

Rahardi, R. K. (2016). Personal and communal assumptions to determine pragmatic meanings of phatic functions. Lingua Cultura, 10(10(2)), 95-98. https://doi.org/doi.org/10.21512/lc.v10i2.897 
Rahardi, R. K. (2017a). Linguistic impoliteness in the sociopragmatic perspective. Jurnal Humaniora. https://doi.org/10.22146/jh.v29i3.24954

Rahardi, R. K. (2017b). Pragmatic phenomena constellation in specific culture dimension language study. International Journal of Humanity Studies, 1(1), 84-92. https://doi.org/doi.org/10.24071/ijhs.2017.010109

Rahardi, R. K. (2018). Elemen dan fungsi konteks sosial, sosietal, dan situasional dalam menentukan makna pragmatik kefatisan berbahasa. Dalam Prosiding Seminar Tahunan Linguistik Universitas Pendidikan Indonesia (SETALI 2018).

Rahardi, R. K. (2019a). Integrating social, societal, cultural, and situational contexts to develop pragmatics course learning materials: Preliminary study integrasi sosial, sosial, budaya, dan konteks situasional untuk mengembangkan materi pembelajaran pragmatik. Studi, 5(2), 169-178.

Rahardi, R. K. (2019b). Pragmatic perspective on phatic functions and language dignity. International Journal of Engineering and Advanced Technology, 8(5C, May 2019), 261268. https://doi.org/DOI: 10.35940/ijeat.E1039.0585C19

Sudaryanto. (2016). Metode dan Aneka Teknik Analisis Bahasa (1st ed.). Yogyakarta: Sanata Dharma University Press.

Unger, C. (2012). Cognitive pragmatics: The mental processes of communication. Journal of Pragmatics. https://doi.org/10.1016/j.pragma.2011.12.001

Wildner-Bassett, M. (2004). Context and culture in language teaching and learning. Studies in Second Language Acquisition. https://doi.org/10.1017/S0272263104290040

Wimberley, E. T. (2017). Ecopragmatics. Ecopragmatics. https://doi.org/10.18848/978-1-61229$613-5 / \mathrm{cgp}$

Wodak, R. (2007). Pragmatics and critical discourse analysis. Pragmatics \& Cognition. https://doi.org/10.1177/0957926593004002006

Yu, K. A. (2011). Culture-specific concepts of politeness: Indirectness and politeness in English, Hebrew, and Korean requests. Intercultural Pragmatics. https://doi.org/10.1515/IPRG.2011.018

Yus, F. (2011). Cyberpragmatics, Internet-mediated communication in context. (A. Fetzer, Ed.) (1st ed.). Amsterdam: John Benjamin Publishing Company. Retrieved from https://benjamins.com 